\title{
Effect of soil $K$-status and bentonite additions on radiocaesium transfer
}

\author{
H. Vandenhove, A. Cremers ${ }^{1}$ and E. Smolders ${ }^{1}$ \\ SCK-CEN, Radiation Protection Department, Radioecology Section, \\ Boeretang 200, $2400 \mathrm{Mol}$, Belgium \\ 1 Katholieke Universiteit Leuven, Laboratory of Soil Fertility \& Soil Biology, \\ Kardinaal Mercieraan 92, 3001 Heverlee, Belgium
}

\begin{abstract}
The influence of bentonite additions and soil $\mathrm{K}$ status on radiocaesium transfer to ryegrass was investigated in a potted soil experiment. A sandy soil was contaminated with ${ }^{14} \mathrm{Cs}$ and amended with $\mathrm{K}$ salts $\left(0-97 \mathrm{mM} \mathrm{kg}^{-1}\right)$ and $\mathrm{K}$ bentonite (0-2\%). After 4 weeks incubation of the mixtures, ryegrass was grown for 18 weeks and trimmed at 7 occasions. During subsequent harvests, the radiocaesium transfer factor (TF) decreased up to 2.7 fold in soils amended with more than $0.25 \%$ bentonite whereas they increased 3.0 to 14.4 fold in unamended soils or at the lowest bentonite application $(0.25 \%)$. Different trends are related to the formation of specific sorption sites and the depletion in soil $\mathrm{K}$ which was more pronounced in soils with $<0.25 \% \mathrm{~K}$-bentonite added. Radiocaesium Interception Potential (RIP) and percentage K bentonite added were positively cortelated. $10-40$ fold higher RIP values at 1 to $2 \%$ supply compared to unamended soils were obtained. Built-up of RIP following subsequent cycles of partial drying and rewetting during plant growth is reflected in a loss in exchangeable $\mathrm{K}$ and the quantitative reduction of the TF. The potential role of $\mathrm{K}$-bentonite as countermeasure for $\mathrm{Cs}$ contaminated soils is discussed.
\end{abstract}

\section{INTRODUCTION}

In the aftermath of the Chernobyl disaster, a great deal of efforts has been invested into the search for agricultural countermeasures that reduce the transfer of radiocaesium from soil to crop to prevent, as much as possible, the entry of radiocaesium into the food chain, thus limiting the radiation dose which results from food intake which may contribute up to $60 \%$ of the total dose to man in the contaminated areas [1].

There is now a general consensus that the solid/liquid partitioning of radiocaesium in soils and sediments - and thus the soil-chemical availability - is govemed by (a) the Radiocaesium Interception Potential (RIP), defined as the product of the FES capacity [Frayed Edge Sites: associated with the micaceous clays (illite) in the soil ([2] and references therein)] and the trace Cs to $K$ selectivity coefficient in the FES and (b) the composition of the liquid phase: $\mathrm{K}$ and $\mathrm{NH}_{4}$ concentration [3-6]. A routine methodology has now been developed [6] for measuring RIPs and $K_{D}$ values can be reasonably well predicted on the basis of RIP and the $\mathrm{K}$ and $\mathrm{NH}_{4}$ concentrations in solution [7]. RIP values of environmental samples cover a range of nearly three orders of magnitude varying between $10 \mathrm{mmol}_{c} \mathrm{~kg}^{-1}$ for organic soils, $100 \mathrm{mmol}_{\mathrm{c}} \mathrm{kg}^{-1}$ for podzolic soils and very sandy sediments and $5000 \mathrm{mmol}_{\mathrm{c}} \mathrm{kg}^{-1}$ for heavy clay soils, chemozems and fine-textured sediments $[3,8,9]$. The upper limit is found for the illite clay mineral $\left(12000 \mathrm{mmol}_{\mathrm{c}} \mathrm{kg}^{+}\right)$.

The general idea underlying countermeasure strategies is two-fold: (a) increasing the soil sorption potential and thus lowering the activity of radiocaesium in the soil solution bathing the plant root (soil chemical) and (b) increasing the soil solution level of cations - potassium in this case - which are competitive in the root uptake process (plant physiological).

Present experiment was designed to study the availability of radiocaesium in soil at widely varying degrees of $\mathrm{K}$-saturation in the exchange complex and covering a broad range of $\mathrm{K}$ concentrations in the soil solution. Both soil chemical and plant uptake aspects are addressed in the study. Homoionic K-bentonite was used as a soil additive to modify the K-saturation of the soil. During the study, we have come across a rather 
extreme case of radiocaesium sorption selectivity. The finding concerns the in-situ formation of a pool of specific sorption sites, following the application of homoionic K-bentonite.

\section{MATERIALS AND METHODS}

The podzol soil, sampled at the nuclear site in Mol (Belgium) is of low CEC (20 mmol $\mathrm{kg}^{\mathrm{d}}$ ) and low RIP $\left(130 \mathrm{mmol} \mathrm{kg}^{-1}\right)$. Other soil characteristcis are presented in Table 1.

\begin{tabular}{|c|c|c|}
\hline \multirow[t]{4}{*}{ Soil solution composition $\left(\mathrm{mmol} \mathrm{dm}^{-1}\right)$} & $\begin{array}{l}\mathrm{K}^{*} \\
\mathrm{NH}_{4}\end{array}$ & $\begin{array}{l}0.86 \pm 0.12 \\
0.30 \pm 0.03\end{array}$ \\
\hline & $\mathrm{Ca}^{2+}$ & $0.70 \pm 0.14$ \\
\hline & $\mathrm{Mg}^{2+}$ & $0.27 \pm 0.06$ \\
\hline & $\mathrm{Na}^{+}$ & $1.30 \pm 0.30$ \\
\hline \multirow[t]{5}{*}{ Exchangeable cations ( $\mathrm{mmol} \mathbf{k g}^{-1}$ ) } & $\mathbf{K}$ & $2.36 \pm 0.25$ \\
\hline & $\mathrm{NH}_{4}$ & $0.74 \pm 0.16$ \\
\hline & $\mathrm{Ca}$ & $13.50 \pm 0.69$ \\
\hline & Mg & $2.07 \pm 0.11$ \\
\hline & $\mathrm{Na}$ & $1.21 \pm 0.15$ \\
\hline $\mathrm{CEC}\left(\mathrm{mmol} \mathrm{kg}{ }^{-1}\right)$ & \multirow{2}{*}{\multicolumn{2}{|c|}{$\begin{array}{l}19.9 \pm 0.8 \\
4.84\end{array}$}} \\
\hline $\mathrm{pH}\left(\mathrm{CaCl}_{2}\right)$ & & \\
\hline Ficld capacity (dm ${ }^{\unlhd} \mathrm{kg}^{+}$) & \multicolumn{2}{|c|}{0.250} \\
\hline Texture $\quad>50 \mu \mathrm{m}$ & \multicolumn{2}{|c|}{95.26} \\
\hline $20-50 \mu \mathrm{m}$ & \multicolumn{2}{|c|}{0.80} \\
\hline $10-20 \mu \mathrm{m}$ & \multicolumn{2}{|l|}{025} \\
\hline $2-10 \mu \mathrm{m}$ & \multicolumn{2}{|l|}{0.30} \\
\hline$<2 \mu \mathrm{m}$ & \multicolumn{2}{|l|}{3.39} \\
\hline $\mathrm{C}\left(\mathrm{g} \mathrm{kg}^{-1}\right)$ & \multicolumn{2}{|l|}{10.0} \\
\hline $\operatorname{RIP}$ (mmol kg-1) & \multicolumn{2}{|c|}{$131 \pm 2$} \\
\hline
\end{tabular}

Two series of soil systems were prepared: 6 samples, of $6 \mathrm{~kg}$ each, containing espectively, $2, \mathrm{l}, 0.75$, $0.5,0.25$ and $0 \% \mathrm{~K}$-bentonite (coded $\mathrm{Al}$ to $\mathrm{A} 6$ ) : series B (coded B 1 to B6) comprising 6 samples (also $6 \mathrm{~kg}$ each) all containing $1 \% \mathrm{~K}$-bentonite. The $6 \mathrm{~kg}$ mixtures of soil and bentonite were mixed with $1.5 \mathrm{dm}^{3}$ solutions (FC) containing the appropriate $\mathrm{KNO}_{3}-\mathrm{Ca}\left(\mathrm{NO}_{3}\right)_{2}$ mixtures (Series $\mathrm{A}: \mathrm{K}$ range of 3-4 mmol dm $\mathrm{m}^{-3} ; \mathrm{Ca}$ range 0.35 to $8.5 \mathrm{mmol} \mathrm{dm}^{-3}$; Series $B$ : $\mathrm{K}$ range 0 to $4.6 \mathrm{mmol} \mathrm{dm}^{-3}$; Ca range of 0 to $\left.11.6 \mathrm{mmol} \mathrm{dm}^{-3}\right)$. A control soil, C, (also $6 \mathrm{~kg}$ ), having received no salts, was also included in the study. All soils were labelled with ${ }^{134} \mathrm{Cs}$ (added to the salt solutions) at $400 \mathrm{~Bq} \mathrm{~g}$ dry sotl. All systems were incubated for 4 weeks to achieve ionic equilibrium. After incubation, soils were characterised in terms of exchangeable cation content, effective CEC (sum of exchangeable cations), soil solution camposition (using ultra-centrifugation-filtration techniques), ${ }^{134} \mathrm{Cs}$ activity in the soil solution (using gamma-spectrometry) and RIP (RIP exp according [6] for $\mathrm{C}, \mathrm{A} 1-\mathrm{A} 6$ and $\mathrm{B} 3$ ).

Soil samples were then subdivided in seven 1 litre pots used for the measurement of ${ }^{134} \mathrm{Cs}$ transfer to ryegrass (Lolium multiflorum L.) in a greenhouse experiment. $0.65 \mathrm{~g}$ seed was used per pot. At two to three weeks' time intervals, rye-grass was harvested and dry weight and K-activity determined for each of the 7 pots. Pots were brought to weight with demineralised water every second day. After the third harvest, soils were fertilised to meet nutrient demand. In total, 7 cuts were harvested, covering a time span of 15 weeks. After the seventh cut, for each of the 13 treatments, 3 pots were taken at random, dismantled and soils separated from plant roots for characterisation as detailed before. All chemical analyses were made in triplicate (except for RIP mess in duplicate). 


\section{RESULTS AND DISCUSSION}

\subsection{Soll Characterisation: built-up of Cs-specific sorption sites}

The discussion relating to the characterisation of the soils used at the start of the transfer experiment (after incubation) is limited to the items relevant to the main issue of this paper (the in-situ generation of specific sorption sites). These items are: soil solution $\mathrm{K}$, exchangeable $\mathrm{K}, \mathrm{RIP}$ and $\mathrm{K}_{\mathrm{V}}{ }^{\left(C_{2}\right)}$. Initial exchangeable $\mathrm{K}$

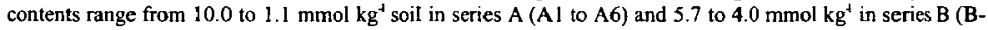
1 to $\mathrm{B}-6$ ). For the control soil, the value is $1.1 \mathrm{mmol} \mathrm{kg}$. The $\mathrm{K}$-concentration ([K]) in the soil solution covers a range of about 10 to $6 \mathrm{mM}(\mathrm{A}-1$ to $\mathrm{A}-6)$ and 6 to $19 \mathrm{mM}$ (B1 to B6). The K-concentration in the control soil is $1.7 \mathrm{mM}$.

RIP values of incubated soils (values not shown) showed a slight increase relative to the control soils (A6 and C), on the average by a factor of about 1.5 to $2.5 . \mathrm{K}_{\mathrm{v}}^{(\mathrm{CS})}$ values are quite low (a range of $10-30 \mathrm{~L} \mathrm{~kg}^{-1}$ ) as could be expected from the low RIP values and the high $\mathrm{K}$-concentrations, [K], in the soil solution.

The results of the soil characterisation data of the "end soils" discussed here are summarised in Table 2. Table 2 shows a summary of in-situ $\mathrm{K}_{\mathrm{p}}{ }^{(\mathrm{Cs})}$ values as obtained from ${ }^{139} \mathrm{Cs}$ activities of the soil and in the soil solution (range of 0.1 to $0.6 \mathrm{~Bq} \mathrm{ml}^{-1}$ ). $\mathrm{K}_{\mathrm{p}}{ }^{(\mathrm{Cs})}$ values cover a range of about 1000 to 6000 , i.e. some two orders of magnitude higher than what was obtained in the soils at the start of the experiment. Measured (RIP ${ }^{\text {nas }}$ ) and calculated RIP (RIP ${ }^{\text {in situ }}$ calculated from $\mathrm{K}_{\mathrm{D}}{ }^{(\omega)} \mathrm{x}[\mathrm{K}]$ ) values of all soils are also shown in Table 2. It is seen that both measured and calculated RIP values are comparable but more importantly it is seen that they have increased drastically. For the $1 \%$ bentonite soils (series B and A2) RIP $=1018(+190) \mathrm{mmol}^{\mathrm{kg}} \mathrm{on}^{-1}$ average, i.e. an increase by a factor of 10 . In series $A$, we clearly witness an effect which is linear in bentonite content.

Table 2: Exchangeable $K, K$ concentration in soil solution, in situ $K_{p}{ }^{\alpha}$ and experimental and in situ RIP values for soils, concentration factors (CF) and transfer factors (TF) after 4 weeks incubation and 5 months ryegrass growth.

\begin{tabular}{|c|c|c|c|c|c|c|c|}
\hline Treatm. & $\begin{array}{l}\text { Exch. K } \\
/ \text { mmol kg.' }\end{array}$ & $\begin{array}{l}\text { Soil solution } \mathbf{K} \\
\text { /mmol L }\end{array}$ & $\begin{array}{l}\mathbf{K}_{\mathrm{D}}^{\text {Cumsitu }} \\
/ \mathrm{dm}^{3} \mathrm{~kg}^{-1}\end{array}$ & $\begin{array}{l}\text { RIP } \\
\text { /mmol } \mathrm{kg}^{-1}\end{array}$ & $\begin{array}{l}\text { RIP }_{\text {in sinu }} \\
/ \mathrm{mmol} \mathrm{kg}^{-1}\end{array}$ & $\begin{array}{l}\mathrm{CF} \\
\Lambda \mathrm{kg}^{-1}\end{array}$ & $\begin{array}{l}\text { TF } \\
\lg g^{-1}\end{array}$ \\
\hline $\mathrm{Al}$ & $5.89 \pm 1.22$ & $3.58 \pm 0.51$ & $690 \pm 84$ & $2098 \pm 358$ & $2470 \pm 758$ & $304 \pm 65$ & $0.44 \pm 0.08$ \\
\hline A2 & $1.29 \pm 0.12$ & $0.92 \pm 0.16$ & $1119 \pm 539$ & $929 \pm 133$ & $1029 \pm 165$ & $416 \pm 204$ & $0.37 \pm 0.04$ \\
\hline A3 & $1.33 \pm 0.18$ & $0.42 \pm 0.11$ & $2214 \pm 1306$ & $770 \pm 79$ & $930 \pm 70$ & $888 \pm 533$ & $0.40 \pm 0.04$ \\
\hline A4 & $1.29 \pm 0.11$ & $0.17 \pm 0.07$ & $2381 \pm 1597$ & $475 \pm 40$ & $398 \pm 58$ & $1006 \pm 704$ & $0.65 \pm 0.09$ \\
\hline AS & $1.12 \pm 0.33$ & $0.09 \pm 0.03$ & $2230 \pm 1071$ & $203 \pm 21$ & $201 \pm 42$ & $6384 \pm 3180$ & $2.86 \pm 0.37$ \\
\hline A6 & $1.03 \pm 0.43$ & $0.04 \pm 0.01$ & $2358 \pm 860$ & $101 \pm 12$ & $94 \pm 31$ & $19118 \pm 7360$ & $8.10 \pm 1.00$ \\
\hline BI & $0.44 \pm 0.02$ & $0.63 \pm 0.17$ & $1502 \pm 633$ & & $946 \pm 131$ & $634 \pm 272$ & $0.42 \pm 0.03$ \\
\hline B2 & $0.51 \pm 0.13$ & $0.80 \pm 0.15$ & $1382 \pm 464$ & & $1106 \pm 218$ & $544 \pm 189$ & $0.39 \pm 0.03$ \\
\hline $\mathrm{B} 3$ & $0.50 \pm 0.12$ & $0.79 \pm 0.12$ & $1233 \pm 319$ & $1084 \pm 187$ & $974 \pm 28$ & $494 \pm 134$ & $0.40 \pm 0.04$ \\
\hline B4 & $0.42 \pm 0.05$ & $0.64 \pm 0.10$ & $2147 \pm 1300$ & & $1374 \pm 28 I$ & $878 \pm 540$ & $0.41 \pm 0.04$ \\
\hline BS & $0.32 \pm 0.03$ & $0.37 \pm 0.08$ & $2550 \pm 1184$ & & $944 \pm 219$ & $1014 \pm 504$ & $0.40 \pm 0.07$ \\
\hline B6 & $0.20 \pm 0.03$ & $0.12 \pm 0.04$ & $6292 \pm 2950$ & & $755 \pm 1.6$ & $2891 \pm 1622$ & $0.46 \pm 0.14$ \\
\hline C & $0.16 \pm 0.05$ & $0.015 \pm 0.002$ & $4340 \pm 2995$ & $75 \pm 18$ & $65 \pm 20$ & $25089 \pm 17310$ & $4.93 \pm 0.76$ \\
\hline
\end{tabular}

Clearly, the formation of specific sorption sites and the loss in exchangeable K (Figure la and Ib), both linear in the dose of bentonite, are interrelated. The subject of $\mathrm{K}$ fixation and the effect of drying is an old one: some 20 years ago $[10,11]$, it was demonstrated that upon prolonged wetting and drying of $\mathbf{k}$ montmorillonite, a mica-like mineral is created. The reorganisation into a collapsed, more ordered micatike structure depends on the number of wetting-drying cycles. It was further shown that specific sorption sites 
could be generated in K-montmorillonite as a result of wetting and drying $\left(80^{\circ} \mathrm{C}\right)$ cycles and that the effect was promoted - not unexpectedly - by increasing the number of cycles [12]. These obscrvations were however limited to laboratory studies on homoionic K-clays and high temperature conditions and were not extended to field scenarios. The surprising aspect in the data presented here is that the addition of initially homoionic K-bentonite to the soil, leads to the formation of an array of specific sites, in spite of the fact that the major portion of the $K$ of its exchange complex is lost and transferred to the exchange complex of the surrounding soil material.
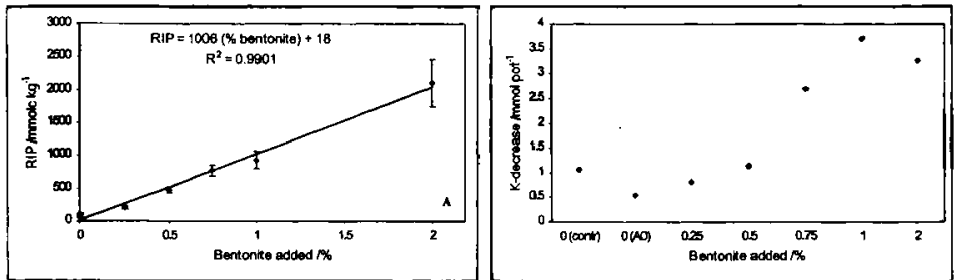

Figure 1: (a) Relation between the percentage bentonite added and the built-up in soil RIP (Series A, "cnd soils"); (b) K decrease for bentonite amended soils of Series A treatments. The balance (decrease) is based on initial exchangeable K + fertilizer K - (plant K) - exchangeable soil $\mathrm{K}$ at harvest seven

It is of interest to quantify the effect per unit amount of bentonite. The RIP ascribable to the bentonitoderived material can be obtained from the difference of the overall RIP of the soil bentonite mixtures and that of the soil. Expressing such difference per gram of bentonite (including all calculated and 5 measured RIPs: A1-A4 and B3), we obtain a value of about $90000( \pm 20000) \mathrm{mmol} \mathrm{kg}^{-1}$. The RIP value of the bentonito derived material exceeds the one of the soil by some three orders of magnitude and that of illite by a factor of 70 .

\subsection{Soil-plant transfer}

Figure 2 shows a summary of the soil-plant transfer factors (TF) for all systems studied and for the seven cuts. In total $91 \mathrm{TF}_{\mathrm{s}}$ were measured (13 systems $\times 7$ cuts) each of the measurements being made sevenfold.

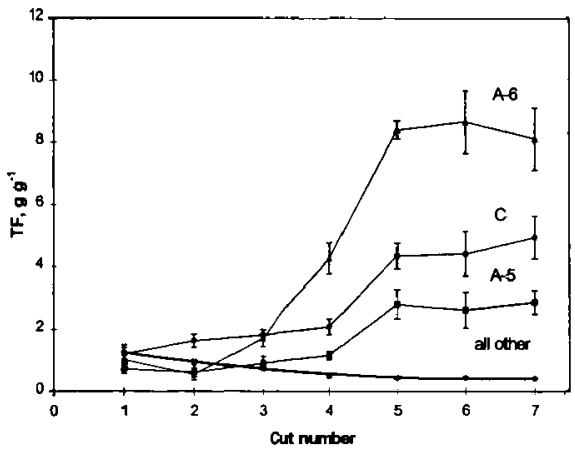

Figure 2: Soil-to-plant transfer factor (TF) for all systems studied for all seven cuts. "all other" shows the average TFs for all systems with $>0.25 \%$ bentonite added (A1-A4 and B1-B6) (ertor bars represent standard deviations) 
In general, reproducibility is quite good : the standard deviation for the $91 \mathrm{TF}$, was $14 \%$ on average (extreme values of 4 and $30 \%$ ). The lower curve gives a summary of all TF values for the systems $A I$ to $A$ 4 and B-1 to B-6 (0.5 to $2 \%$ bentonite). No significant differences in TF were found among hese 10 systems for each of the seven cuts. Each data point in the figure is thus an average of 70 observations. Clearly, the steady decrease in TF for treatments with more than $0.25 \%$ bentonite added, reflects the buildingup of the FES pool, apparently completed at the $5^{\text {th }}$ cut. The overall TF average of 5 th, 6 th and 7 th cut, for the 70 TF values (each obtained as the mean of 7 replicas) is $0.425( \pm 0.036)$. If we consider the value of the intercept on the TF axis as representative for the RIP status at the end of soil incubation (i.e. the start of the transfer experiment) then the ratio of this intercept and the plateau value of TF towards the end of the experiment, can be taken as a quantitative measure of the growth of the RIP during the uptake experiment. Such ratio is 4. Remembering that the RIP values of the soils ( $1 \%$ bentonite) at the end of incubation had increased by a factor of 1.5 to 2.5 , relative to the original soil, then we see an exact agreement between the effect on $\mathrm{TF}$ and the change in RIP from the original soil to the one analysed at the end of the transfer expeniment, i.e. a factor of 10 .

The constancy of TF values for any given cut, irrespective of the K status (for systems A-1 to A-4 and B1 to $\mathrm{B}-6)$ deserves some special comment. It can be rationalised on the basis of the effect of $\mathrm{K}$ concentration in the soil on $\mathrm{K}_{\mathrm{D}}{ }^{\mathrm{Cs}}$ and the concentration factor $\mathrm{CF}$, defined as the radionuclide ratio in the plant biomass (shoot) to that in the soil solution. Of course TF can be written as :

$T F=\frac{C F}{K_{b}^{C}}$

The table gives a survey of the $\mathrm{CF}$ values as obtained from ${ }^{134} \mathrm{Cs}$ activities in the soil solution after cut 7 . It is seen that CF values (A-1 to A-4 and B-1 to B-6) cover a range of 300 to about $3000 ; \mathrm{K}_{v}{ }^{\text {(Cs) }}$ covers a range of 700 to 6300 ; also one order of magnitude. So we witness for a $\mathrm{K}$ concentration range of 3.6 to 0.17 $\mathrm{mM}$ an exact compensation between $\mathrm{CF}$ and $\mathrm{K}_{\mathrm{p}}$ : lowering $\left[\mathrm{K}\right.$ ] leads to an increase in $\mathrm{K}_{\mathrm{v}}$ which is exactly paralleled by a linear increase in $\mathrm{CF}$, resulting in an invariance in TF. Similar conclisions were formulated just recently [13] with regard to the insensitivity of TF to $\mathrm{K}$ concentration in a high $[\mathrm{K}]$ range ( $>1 \mathrm{mM})$.

TF values for the control systems are seen to be higher (after cut 5) by a factor of $10(\mathrm{C}: \mathrm{TF}=4.3$ to 5.8 ) and 20 (A-6: TF $=8.1$ to 8.7). Comparison between $\mathrm{B}-6$ and $\mathrm{C}$ shows that $\mathrm{K}_{\mathrm{D}}{ }^{\dagger \mathrm{Cs})}$ values for the two are similar (as can be expected on the basis of RIP and [K] values). However, the very low [K] value in the control leads to a very sharp increase in CF, thus leading to a tenfold increase in TF. The A-6 system shows a very high $\mathrm{CF}$ as well and the $\mathrm{K}_{0}{ }^{(\mathrm{Cs})}$ value is half the value of $\mathrm{C}$, i.e. the radiocaesium level in the soil solution is twice as high; accordingly $\mathrm{TF}$ is twice as high as well.

The system A-5, with $0.25 \%$ bentonite shows TF values intermediate between the $1 \%$ bentonite systems and $\mathrm{C}(\mathrm{TF}=2.75)$. Again, this is essentially the result of a sharp increase in the CF at the low [K] value : $K_{D}{ }^{(C s)}$ values of $A-4$ and $A-5$ are identical but $C F$ values differ by a factor of 6 .

\section{CONCLUSIONS}

It has been shown that the building-up of the radiocaesium interception potential of a soil, resulting from the application of K-bentonite and the in-situ generation of specific sorption sites is quantitatively reflected in a reduction of the soil-plant transfer.

In conclusion, it is of interest to comment on the practical feasibility of countermeasures, based on the use of K-bentonite. We are faced with two effects : an enhanced sorption effect, resulting from RIP increase and a fixation effect. The sorption effect, depending on bentonite dose and relative RIP values of soil and bentonite, can be approximated by the equation :

Sorption $\cdot$ effect $\cdot \approx \cdot 1 \cdot+\cdot f_{b} \cdot \frac{R I P_{b}}{R I P_{s}}$

where $f_{b}$ refers to the fraction of bentonite added and RIP and $\mathrm{RIP}_{b}$ to RIP values of soil and bentonite. A distinction has to be made between two scenarios. Firstly, when the deposited activity is concentrated in the upper 2-3 mm (i.e. directly after an accident); secondly, when the radiocaesium activity is distributed over the plough layer. 
In the first case, countermeasure strategy could be based on the use of bentonites of medium-level RIP performance, say $20000 \mathrm{mmol}_{\mathrm{s}} \mathrm{kg}^{-1}$, applied as a dry mix of bentonite- $\mathrm{K}_{2} \mathrm{CO}_{3}$ (the most efficient procedure) at relatively low dose. Application rates of the order of 2 ton ha ${ }^{-1}$ correspond, when expressed with respect to soil mass of the upper $2-3 \mathrm{~mm}$, to a dose of $5 \%$. The RIP boost, corresponding to such a dose, is $1000 \mathrm{mmol}_{\text {, }}$ $\mathbf{k g}^{-1}$, high enough to bring about a fixation effect in the range of $8090 \%$, i.e. a one order of magnitude effect (combined sorption and fixation) can be anticipated.

The situation is somewhat more complex when dealing with a scenario years after the event. In such a case it would be appropriate to rely on bentonites in the upper end of the RJP scale. Surface application would of course be a first step for allowing built-up of RIP by WD. Furthermore, higher application rates may be necessary : e.g. a dose of 10 ton ha ${ }^{-1}$ would correspond to a RIP boost, expressed over the top $25 \mathrm{~cm}$ of soil, of just about $200 \mathrm{mmol}_{\mathrm{c}} \mathrm{kg}^{-1}$. Whether this would be adequate to lead to significant fixation yields is difficult to assess at this stage and field trials should be necessary to optimise countermeasure strategy.

\section{REFERENCES}

1. Strand P., Balonov M., Skutend L., Hove L., Howard B., Prister B.S., Travnikova, 1., Radnikov, A., in "The radiological consequences of the Chemobyl accident", A. Karaoglou et al. Eds. (Eur. 16544. ENLuxembourg, 1996) pp. 261-269.

2. Cremers, A., Elsen A., De Preter P., Maes A., Nature 335 (1988), 247-249.

3. Sweeck L., Wauters J., Valcke E., Cremers A., "The specific interception potential of soils for radiocaesium", Transfer of Radionuclides in Natural and Semi-Natural Environments, G. Desmet et al., Eds. (Elsevier, Barking, UK, 1990) pp. 249-258.

4. Cremers A., et al., in Transfer of Radionuclides in Natural and Semi-Natural Environments, G. Desmet et al., Eds. (Elsevier, Barking, UK, 1990) pp. 243248.

5. Comans R.N.J., Middelburg J.J. Zonderhuis J., Woittiez J.R.W., De Lange G.J., Das H.A., Van der Weijden C.H. M., Nature 339 (1990), 367-369.

6. Wauters J., Elsen A., Cremers A., Konoplev A.V., Bulgakov A.A., Comans R.N.J., J. Appl. Geochem. (1996) 589-594.

7. Wauters J., Elsen A., Cremers A., J. Appl. Gexhem. 11 (1996) 601-603.

8. Rauret G., Firsakova S. The transfer of radionuclides through the terrestrial environment to agicultural products, including the evaluation of agrochemical practices. Experimental Collaboration project $\mathrm{n}^{\circ} 2$, Final report (Eur. $16528 \mathrm{EN}$. Luxembourg, 1996) pp 181.

9. Wauters J., Madruga M.J., Vidal M., Cremers A., Sci. Total Environ. 197 (1996), 121430.

10. Gaultier J.P., Mamy, J., Clay Miner. 13 (1978), 139146.

11. Plançon A., Besson G.N., Gaultier J.P., Mamy J., Tchoubar C., "Qualitative and quantitative studyof a structural reorginization in montmorillonite after potassium fixation", Proc. Int. Clay Conf. Oxford, 1978 M.M. Mortland and V.C. Famers, Eds. (Elsevier, Amsterdam, 1979) pp 45-54

12. Maes A., Vanderheyden D., Cremers A., Clays \& Clay Min., 33(3) (1985)251-257

13. Smolders E., Van den Brande K., Merckx, R., Environ. Sci. Technol. 31 (1997) 34323438. 